\title{
The Montessori Educational Method: Communication and Collaboration of Teachers with the Child
}

\author{
Hatice Uslu Kocabaş* \\ Yıldiz Technical University, Istanbul, Turkey \\ ORCID: 0000-0002-0380-3031 \\ Bünyamin Bavlı \\ Ylldız Technical University, Ístanbul, Turkey \\ ORCID: 0000-0002-7274-0935
}

Article history

\section{Received:}

01.03.2021

Received in revised form: 08.06.2021

Accepted:

26.07.2021

Key words:

Montessori method;

Communication;

Collaboration;

Montessori teachers
Montessori learning environments, described as prepared environment, allow children to choose their work freely and construct their own learning. Because the child is in the center and the roles of the teacher differ from the roles of the teachers in traditional schools, the direction of the communication and collaboration between the child and the teacher is determined accordingly. This study aims at examining the practices of Montessori teachers in communication and collaboration with the child. A phenomenological approach was adopted in the study. Purposive snowball sampling was employed to identify 12 Montessori preschool teachers. A focus group interview and semi-structured interviews were used to obtain data. The obtained data were transcribed and analyzed through the content analysis method. The findings were examined under three main themes, which are "the communication of the teacher with the child", "the collaboration between the teacher and the child" and "the difficulties Montessori teachers face in communication and collaboration with the child". The study showed that teachers' communication approach was based on respect for the child. When communicating with the child, teachers adopted a guidance role. However, teachers' practices in communication deviated from Montessori philosophy in case of conflict and undesired behaviors. Support from the child's peers, involving the children in forming class rules, giving children responsibility, and collaboration in learning were the main subjects that maintain collaboration with the child. Besides, study findings indicated that Montessori teachers faced some difficulties in communication and collaboration with the child. The results of this study imply that the communication and collaboration practices of Montessori teachers and the Montessori philosophy are mostly in line but can contradict in some cases.

\footnotetext{
* Correspondency: haticeuslukocabas@gmail.com
} 


\section{Introduction}

Today, preschools provide the education to prepare children for elementary school as well as to support their development in many ways. These institutions fill in the gap by meeting the need for creating a social environment that emerges in parallel with the changing life standards. Having such a crucial function, some preschools adopt different teaching methods in practice. One alternative in this method diversity is the Montessori method. According to Montessori, the aim of education is to raise free children who know what they want to do and what they are doing (Wentworth \& Wentworth, 2013). In order to reach this aim, Montessori created a child-based educational method. Schools adopting Montessori method have specific features. For instance, teachers have some standards following the Montessori training. Teachers have the skills to teach multi-age groups based on the developmental stages. In addition to that, teachers have awareness of Montessori teaching materials. On the other hand, children at a school where Montessori method adopted have some specifications, as well. Children have the privilege of freely move to conduct their own work without interruption (American Montessori Society, 2021). The prepared environment that serves as the implementation platform according to these core components, is the learning environment that is prepared before according to the child's development and which enables the child to move freely within the classroom. In this environment, the child has the right to choose learning activities defined as 'work' (Lillard, 2013). Montessori method is integrated within the prepared environment, child and teacher triangle (Lillard \& McHugh, 2019). This integrity shapes the dimension of the relationship between the teacher and the child. Montessori teachers design the learning environment according to the child's development and needs. During the learning process, teachers function as a guide for children to display their potentials through their observations (Aljabreen, 2017). The number of studies, examining the communication and collaboration between teachers and children in Montessori classrooms from the perspective of teachers, are limited. For this reason, it was aimed to fill this gap by identifying the preferences and experiences of preschool teachers, who conduct the Montessori method, which they adopt in communication with children.

\section{Philosophical Assumption of Montessori Method and Its Reflection to Learning Environment}

With respect to educational philosophy, Maria Montessori adopted a progressive educational philosophy. The Montessori philosophy is theoretically in line with the school of thought of Rousseau, Pestalozzi, Seguin and Itard (Edwards, 2002). Montessori rejected punishment and reward methods due to the idea that a child's desire should be shaped through an external discipline (Montessori, 2004). While being progressive, Maria Montessori also draws attention to cognition by being a pioneer in the field of cognitive psychology (Ornstein, 2016).

The Montessori educational philosophy gives the opportunity for the child to move independently and progress at his own pace within the prepared environment by reformulating the perception of school. In prepared environment, children have the opportunity to move freely without being dependent on an adult (Montessori, 2004).

In the Montessori learning environment, an uninterrupted work cycle is presented to the child in a dynamic process and the child's desire to learn is triggered (Greene, 2005). During the uninterrupted work cycle, children can choose and work with the materials that they have been introduced to before. A child who has completed his/her work is expected to properly place the material back to its place on the open shelf. Children mainly work individually 
(Lillard, 2007) but they may also work in small groups (Whitescarver \& Cossentino, 2008). In addition, during circle time activities, the whole class has an opportunity to come together (Lillard, 2012). In the classroom setting created in such a system, classroom management is different from the classroom management perception that requires children to sit collectively during education (Montessori, 2004).

A respect-based classroom atmosphere is underlined in the Montessori learning environment. Desired positive outputs in Montessori classrooms are obtained through the collaboration between the teacher and the child (Estes, 2018). Collaboration based learning and the communication style that children establish with adults reach ideal outputs that are aimed at (Lillard, 2007). In addition, in Montessori classrooms, where children from various age groups interact, children are in solidarity with each other, especially elder children help younger children, and collaboration takes place rather than competition (Flynn, 1991). Based on this, undesired behaviors are less observed in Montessori classrooms when compared to traditional classrooms (Brock, 2017; Duckworth, 2008; Lillard, 2018; Mushamba, Burney, \& Kent, 2017).

Maria Montessori considers education as a whole with moral, mental and emotional dimensions rather than focusing on mental development (Duckworth, 2006). Thus, learning to communicate in a peaceful framework in Montessori classrooms is one of the priorities for teachers and students (Thayer-Bacon, 2011). However, there are also children who display negative behaviors in Montessori classrooms. According to Montessori, negative behaviors of children are observed due to children failing to fulfill the responsibility of moving freely. Children performing negative behaviors generally need to stay close to the teacher and are deprived of the right of moving freely within the classroom. In such cases, the teacher approaches the child with sympathy and deals with the issue in person (Lillard, 2007). As a result, Montessori teachers, as well as the Montessori environment, have a crucial mission in shaping classroom communication and collaboration.

\section{Montessori Teacher: Roles and Responsibilities}

In Montessori classrooms, the teacher undertakes the role of a guide directing the child to self-education appropriate with the child's development (Montessori, 2004). Montessori teachers offer help and support to the child according to the needs. This support is reduced to minimum during the educational process (Edwards, 2002). This presents that the teacher does not interfere with the child unless it is necessary. The teacher, defined as the classroom manager, is the coordinator of a system in which children control their behaviors during their work. Montessori teachers are in collaboration with the children during this self-education process (Montessori, 2004). This requires the teacher to stand against an external authoritarian figure who orders the child what to do and how to behave (Harris, 1995). Therefore, the purpose of the Montessori teacher is to help the development of self-confidence and internal discipline of children (Edwards, 2002). The fact that children can prefer their own activities in the learning environment gives the opportunity to ensure internal discipline. Self-confidence and internal discipline of children contribute to Montessori peace education. Montessori believes values such as respect, global citizenship, and responsibility, skills such as passion and imagination contribute peace education (American Montessori Society, 2021; Duckworth, 2008; Signorello, 2017).

Respect for the child is one of the principles of the Montessori method (Isaacs, 2018; 
Pickering, 1992). In accordance with this, Harris (1995) emphasizes that Montessori teachers encourage children to establish politeness-based communication with each other. Teachers should be careful to lower their voice tones and be a role model with their moral, behaviors and posture (Montessori, 2009).

Montessori (2009) underlines that education is carried out with the collaboration between the teacher and learning materials. Montessori teachers undertake a passive role during the children's learning process rather than being active (Montessori, 2013). Teachers observe like a researcher who tries to scientifically interpret the process during the work cycle of children. Teachers who constantly and carefully observe the child present the child new work when he is developmentally ready for a new one (Whitescarver \& Cossentino, 2008). The teacher who undertakes a guide role has also the duty of ensuring a need-oriented environment by constantly observing the children in the learning environment (Baynham, 2016). Hence, teachers should "set a prepared environment according to the child's needs" (Bărbieru, 2016, p.12).

In the Montessori approach, the individual and social development of the child is supported through the teacher, free work of the child and prepared environment. Therefore, putting forward the communication and collaboration established between children, who are at the center of learning by following their own preferences in a prepared environment, and Montessori teachers, who support the children as guides by observing them, will contribute to revealing the link between the Montessori philosophy and the practice. Recent literature focuses on language teaching, inclusive education, motor skills, psychosocial development and Montessori method (Dereli, 2017; Ender, \& Ozcan, 2019; Firdaus, 2018; Hiles, 2018; Kusumawardani, Nani \& Sulistiani, 2020; Sar1, \& Türk, 2020) but includes few studies examining the communication and collaboration between teachers and children in Montessori classrooms from the perspective of teachers. To that end, it was aimed to fill this very gap by identifying the preferences and experiences of preschool teachers, who conduct the Montessori method, which they adopt in communication with children. Current study aims to explore communication and collaboration of teachers with the children at the Montessori preschools.

\section{Method}

\section{Research Design}

The phenomenological method, one of the qualitative study methods, was employed in this study. The phenomenological study output refers to gathering individually experienced facts around common principles (Creswell, 2012). Current study involves teachers teaching at the Montessori schools. It is evident that teachers taking part in this study have rich experience of adopting Montessori Method. Thus, it is believed that the phenomenological method is an appropriate method for the purpose of this study. The researcher refrains from present judgments in empirical phenomenological studies (Creswell, 2012). In this study, identifying the preferences and experiences of Montessori teachers, which they adopt during their communication and collaboration with the child with an empirical approach, was preferred. Therefore, semi-structured interviews and focus group interviews were carried out with preschool teachers who implement the Montessori Method. Focus group interview is one of the most adopted data collection method in qualitative studies. "It is an attempt to learn about the biographies and life structures of group participants" (Berg, 2014, p.111). 


\section{Study Group}

The aim of phenomenological studies is to put forward what the phenomenon is rather than generalizing the results (Converse, 2012). For this reason, a study group, which is wide enough to transfer rich and deep information but small in size, is selected purposefully (Chamberlain, 2009). Twelve female Montessori teachers aged between 23 and 38 and who have experience in Montessori preschools, were identified through the snowball sampling method. Five teachers have associate degree, six have bachelor's degree and one has master's degree. The teachers took Montessori education in various universities and institutions in Turkey and overseas. Experiences of the teachers in Montessori classrooms range between 6 months and 10 years. The most recent professional development activities carried out by the teachers were stated as national and international trainings and conferences as well as readings they did individually. The teacher with the nickname Jane does not know Turkish and works as an English language teacher in a Montessori school giving bilingual education.

\section{Data Collection}

Study data were collected through one-to-one interviews and a focus group interview. Interviews are effective data collection instruments in cases when the perceptions and interpretations of the participants about a certain issue are tried to be explored (Berg, 2019). A semi-structured interview protocol was executed in this study because experiences of Montessori teachers concerning the communication and collaboration with children are discussed phenomenologically. The semi-structured interview protocol was designed with open-ended questions (Creswell, 2012). Semi-structured interviews are more appropriate interview techniques for educational studies because they give the opportunity to get flexible answers (Türnüklü, 2000). Expert opinions were resorted to before conducting the interviews and a pilot interview was carried out with a Montessori teacher to test the questions. Interview questions got their final form based on the data gathered from expert opinions and pilot interview.

Focus group interview was also conducted along with semi-structured interviews so as to collect data. Focus group interviews provide the opportunity for participants with common grounds to express their ideas and emotions and widen their answers through group interaction. Thus, it is used for supporting other data along with providing a basic data resource for a research (Berg, 2019).

The time that the researchers planned for the interviews were interrupted by the Covid-19 pandemic. For this reason, the interviews were conducted distantly through video conferences due to health precautions and to ensure social distancing. One-to-one interviews were carried out on a total of 7 participants for about an hour for each participant. The interviews were recorded with a voice recorder. The focus group interview took almost 2 hours and 15 minutes was recorded through the Zoom application. In addition, every question asked by the participants was answered by the researchers in detail and thus, hesitations of the participants were cleared away. Data collected by the interviews were transcribed by the researchers who carried out the interviews. The researchers then analyzed interview records that were transcribed.

\section{Data Analysis}

During the data analysis phase, data collection, data reduction, data displaying and conclusion drawing take place repeatedly (Miles \& Huberman, 1994). Throughout the data analysis stage of this study; data unrelated to the subject were reduced, data were analyzed 
through the content analysis method and results were attained as a result of repeated analysis. "Content analysis, which generally prescribe systematic counting, indexing, and categorizing of elements" (Saldaña, 2013, p.53). In this respect, researchers first of all developed the codes. Depending on the codes, categories and themes were developed. In this cyclical process, researchers always reviewed the data again and again. Researchers obtained the codes, categories and themes related to the study subject as a result of content analysis. Content analysis gives the opportunity to indirectly interpret the communication of people (Fraenkel, Wallen, \& Hyun, 2011). Thus, explanation and comments were made about the subject based on the codes, category and themes created concerning the communication and collaboration experiences of Montessori teachers with the child.

\section{Validity and Reliability}

Various precautions were taken to ensure validity and reliability of the study. After the interview questions were prepared arrangements were made based on expert opinions. A pilot interview was conducted before the interviews so as to identify the effectiveness of the interview questions, whether or not the questions are appropriate for the study purpose was evaluated and study consistency was ensured (Berg, 2019; Türnüklü, 2000). How interview questions are perceived by the participants and to what extent the answers are related to the subject were evaluated after the pilot study with the Montessori teacher who conducted the pilot study.

Various data collection methods were used through diversification so as to increase the credibility of the study findings. It is not possible to reach certain, in other words objective, reality due to the nature of qualitative researches. In addition to the one-to-one interviews conducted to collect study data, focus group interview was also carried out where participants reminded each other about the various aspects of the study through a group dynamic.

Open-ended questions were asked to the participants during the interviews to avoid interfering with their ideas and experiences but various non-directive questions were asked for them to clarify the subject when necessary.

Sharing voice records with the relevant participants as transcripts gives the participant the opportunity to review his own statements. This reinforces study validity (Türnüklü, 2000). In this study, voice and video records were shared with the participants for confirmation as texts after the interviews conducted with participant teachers. After participant confirmation, interviews were analyzed one-by-one by the researchers. The codes, categories, and themes that were generated after the analysis were subject to expert opinions to verify them which is also called peer debriefing. In this respect, researchers presented the generated codes, categories, and themes to other researchers, who have experience and knowledge about the research topic, for the review. Following the review process, researchers conducted minor changes on some codes.

\section{Ethical Consideration}

One point that needs to be dwelled upon in qualitative studies is ethics. At this point, informing and ensuring the rights of the participants comes to the agenda. Before the interviews that were conducted as the data collection method of the study, the purpose and content of the study was expressed and it was stated that participation is voluntary based and that the participants can leave the interviews whenever they want without giving any excuses. They were informed that audio and video records will be taken during the interviews and the 
consent of the participants was taken. Participating in the interviews with one's own will can be considered as a signed document approved by the participant. In social studies, ensuring participant confidentiality is the responsibility of researchers (Berg, 2019). In order to ensure confidentiality, personal information of the participants was carefully protected and nicknames were used rather than real names in citations of participant statements.

\section{Role of the Researcher}

One of the researchers is a Montessori teacher who has an American Montessori Society (AMS) certificate. This researcher has conducted observations and implementations in various schools in Texas, the USA and worked in Montessori schools. The other researcher was an expert in the field of Educational Sciences and has experiences in educational research, educational national and international projects. The researcher is also a part of the study in qualitative studies. But this also attaches various roles and responsibilities to the researcher. At this point, researchers conducted the interviews by avoiding their own experiences and judgments so as to sustain their objectivity (Merriam, 2015). The researchers categorized the data they collected from the participants according to the subject, made citations and gathered the principles of the phenomenon (Creswell, 2012). They also maintained their objective attitude during the data analysis phase.

\section{Findings}

Based on the data collected from Montessori teachers, three main themes were created; communication of the teacher with the child, collaboration between the teacher and the child and difficulties teachers face in communication and collaboration. Categories that were classified according to the subjects were examined in detail under each theme.

\section{Communication of the Teacher with the Child}

Participant statements concerning the communication of the teacher with the child consisted of; guidance role of the teacher, recognizing the child, greeting, one-to-one communication with the child, group communication and communication in cases of conflict and disagreement. Categories created based on these themes are summarized in Figure 1.

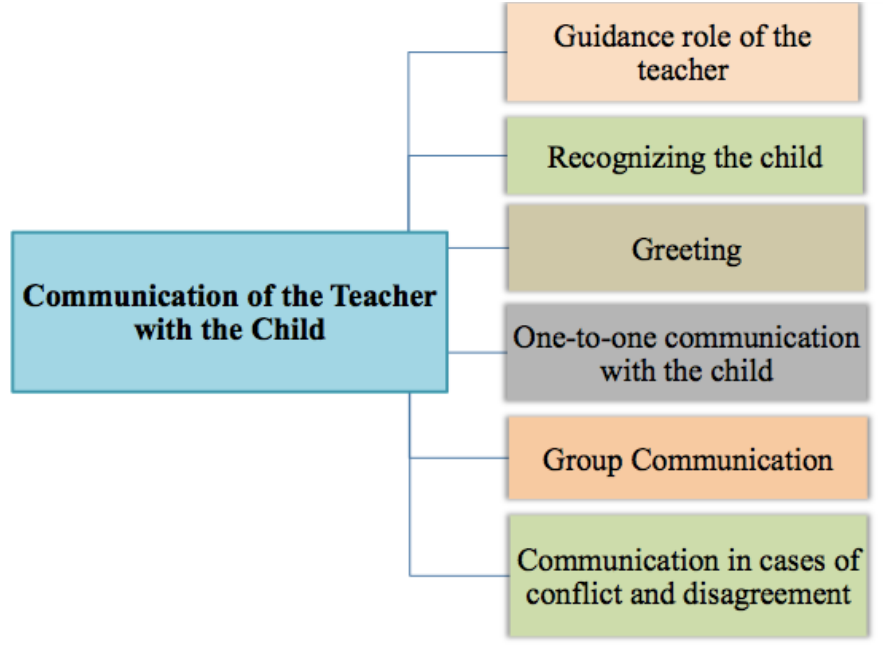

Figure 1. Categories examined under the communication of the teacher with the child theme

In definitions concerning teacher communication with children, it is evident that respect for the child, which is the basis of the Montessori method, is underlined and that the teacher 
identifies his position in child communication as a guide and an advisor. As a teacher, Ümran defines her position in child communication as "I want to show myself as a guide, a helper, an advisor. And that's how I begin with the child."

The teachers stated that they adopt a communication style convenient for the differences and needs of the child. Therefore, the importance of recognizing and understanding the child according to the observations was underlined. Gül emphasizes the importance of observation in communication as "Observation comes first in communication with the child. I believe that observation is crucial. Because there are personal differences between adults and children due to our nature and the way we are raised up."

Different teachers restated that communication should be gradually constructed on a bond of trust after starting communication based on observations. With this respect, the teachers underlined that they approached the child in a positive attitude during communication from the first day on. Adopting an approach that considers the emotional needs of the child, appropriate for the developmental level of the child was underlined in ensuring a bond of trust. In ensuring trust during child communication; talking at the child's level, making eye contact and taking into consideration the child's emotions are the points emphasized. Rukiye explained this as "We lower ourselves to the child's level when we want to communicate with the child". Tuğçe said "First observation, then approaching the child's area of interest. [...] Then bending down, making eye contact, sharing our emotion with the child. [...] I think that emotion is the key of education".

One other category that was expressed concerning communication during the interviews was greeting. Greeting, which starts communication in the morning after the first interaction, was stated to occur one-to-one between the teacher and the child and also as a group between the teacher and the whole classroom.

Teachers, who underlined that they find one-to-one greeting in the morning very important, stated that they start communication by trying to begin the day good by paying attention to the child's mood, needs and facts like being sleepy. It was stated that after the one-to-one greeting that takes place in the morning at the entrance, the teacher and the children greeted each other as a group in the greeting circle. Fikriye stated these about the greeting circle:

[...] as a society sharing the same setting, I mean as the children in the same classroom, together with the teachers, we get the chance to see and greet each other. Because when the child comes to school on his/her own, he might not have the opportunity, not feel willing to or not prefer to greet all his friends. But I think it is important for us to greet each other all together, to know how we all are and become aware of this.

In the greeting circle; an interactive group setting is established between the teacher and children through the "hello song", asking about health, the weather chart and calendar activities. Furthermore, it was stated that in schools giving bilingual education greeting takes place with the teachers who give education in Turkish and English separately in both languages.

Montessori teachers establish one-to-one communication during the child's uninterrupted work cycle. All of the participant teachers stated that carrying out the activities individually gives positive results because it provides one-to-one communication opportunity to the child and teacher. It was stated that ensuring one-to-one communication between the teacher and 
the child helps getting to know the child more closely and facilitates determining the individual differences, pace, needs and readiness of the child. Thus, a basis is created for the teacher to guide the child according to the child's learning styles and pace.

I can communicate with the child better when I work individually with the child. We express ourselves more comfortably, we actually express according to the child and only to that child. That's why I think it is more effective and better with respect to individual activities and teacher-child relationship. (Fikriye)

During the communication established with the child the importance of being simple, clear, straight and intimate and being careful about tone of voice while talking and using appropriate statements for the child was underlined.

I mean not like talking normally with a friend but so that the child can understand, clearly and being careful with the tone of voice. [...] When adults get into detail when speaking with a child they see the child as an adult and go into unnecessary details. This can lead to confusion in the child's world. That's why you should be simple. (Fulya)

It is evident that Montessori teachers guide the children by preferring a humble, polite and gentle language in child communication. In participant teacher statements it was underlined that how one should speak according to the rules of grace and courtesy and how tone of voice should be tuned in the classroom is expressed and carried out during the orientation period. Jane emphasized the importance of grace and courtesy metalingual communication in child communication as "You have to keep your tone of voice slow, you have to be open in your talk, you have to show lots of, lots of grace and courtesy in your talk."

Teachers stated that when there is noise in the classroom at an accelerating tone that disturbs the children, they go to a corner and observe the children. When the disturbing noise is made by more than one child then teachers talk with the children about the act and encourage their friends to show empathy and not get disturbed by the noise. When there is noise in the classroom at an accelerating tone that disturbs the children, teachers grab the children's attention through stimuli like bells or when it is dark outside by turning the lights off and on and reminds them about voice tone rules. The fact that responsibility about reminding is also given to the child other than the teacher is significant. Asl1, who realizes that there is an increase in children's voice tones during the uninterrupted work cycle, holds an emergency meeting by gathering the children in a circle and provides the children an opportunity to give reflective opinions about the reasons of the noise. Activities that are oriented towards needs are carried out after the children express their ideas. "We have a circle hour bell. I ring it. Then I say, "children it is now circle time". [...] We create the circle. We hold a meeting, if there is too much disturbing noise..."

The teachers stated that when they observe a positive behavior they express polite statements showing they realized it. Gülten explained her attitude against a positive behavior of the children as "I usually thank the child for a positive behavior. This makes the child happy; his friends gain awareness after this attitude." She added that she prefers using positive sentences to warn about negative issues and stated that "For example we don't run in the classroom but we don't tell the children that we don't run. We walk slowly in the classroom, we can run in the garden. [...] I try to change it to a positive sentence".

Negative states also occur in Montessori settings that are described as peaceful. There can be 
children who lead to conflict and disagreement during the uninterrupted work cycle. Teachers underlined that they follow the state by observing and interfere with the child at a point they find it necessary. In this case, they stated that they communicate with the child undergoing conflict and disagreement and direct him to other work; they give him responsibility or apply the peace table method. Rukiye stated "If the child forces me, how should I say, I direct him to the thing he loves most." Nurten expressed "The issue can extend between children, like with adults. In such cases I appoint one of the children and send him to another classroom. [...] We continue by suspending from the setting by giving responsibility."

Although individual work is more dominant in Montessori 3-6 years old classrooms, there is also an opportunity for mass communication between the teacher and children during the circle time where the whole class comes together and shares experiences. With respect to the communication between the teacher and the group in the circle, Ümran stated, "The circle is not side-by-side, one after another or rowed. It is a round circle where we can make eye contact. This is crucial for us". It is evident in the interviews that the number and duration of circle hours carried out by the teachers a day differs. Teachers stated that the circle time takes about 15-20 minutes depending on the needs of the children, their attention duration and according to the activity.

Jane, was raised in a different geography (in a part of South Asia) and has Montessori teaching experience in a country other than Turkey, stated that the communication between the teacher and child is more intimate in Turkey than in her own country. She expressed the fact that the child communication approach changes during the process due to cultural grounds with these statements:

Because, over here, it's like (showing) very open with the children. And if you are like shaking hands, like we used to be trained like in a Montessori environment, like you have to be great calm and patient that actually doesn't work for me, I tried that as well. [...] So when I used to shake hands vey calmly, then I changed it into like, you know, more of the open expressions and happy expressions to them and this is what normally we don't do in the Montessori environment. You are vey nice and smile actually. But yeah, it depends on the culture.

During the interviews there were teachers who stated physical contact as an important factor in child communication. But it was added that hugging and touching took place according to the child's permission. Some of the participant teachers emphasized that they preferred to hug the child during the first interaction in the morning.

\section{Collaboration between the Teacher and the Child}

Under the collaboration between the teacher and child theme are; communication and reliability in collaboration, participative rule making, duty and monitoring, collaboration between teacher and child's peers, collaboration in learning categories. These categories were brought together in Figure 2. 


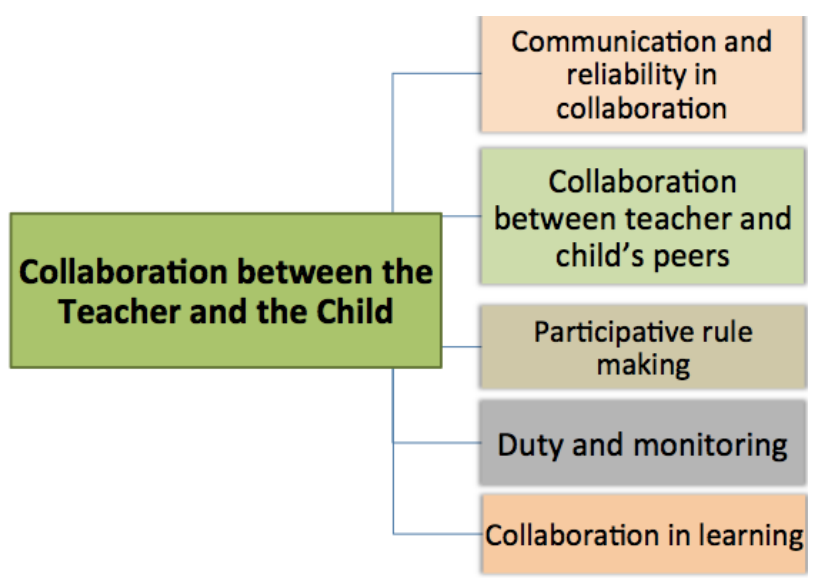

Figure 2. Categories examined under the collaboration between the teacher and the child theme

According to the participant teacher statements, it can be asserted that the grounds of collaboration can be laid through a healthy communication established between the teacher and child. Jane expressed this as "Collaboration from the teacher's perspective is, again one thing, it is about communication, how you communicate with the child." Therefore, the importance of establishing a bond of trust between the child and teacher and considering the individual differences of the child in collaboration was emphasized. Fulya stated "In the Montessori educational philosophy the most important point that we contribute to concerning collaboration is; gaining trust, revealing the child's potential, helping the child's satisfaction of success."

With respect to the collaboration with children, teachers underlined the rules they apply determinately. Classroom rules are introduced to the children during the adjustment to the Montessori learning environment. There were teachers who stated that they applied democratic rule making activities in the learning environment by collaborating with the children in the circle. Children play an active role in determining classroom rules and adapt to the Montessori environment with their own initiative through these activities. Gülten explains the rule making process they apply with the participation of the children as:

I make them sign for example an agreement as a whole classroom. For example, if we disagree on something, not only for disagreements though, or I ask them. I ask what rule should be applied right now, it changes according to the state. For example, which items would you like to be in our classroom. I prepare things to include them in the process and we write on the paper together. Then they sign it.

With respect to child collaboration established in the classroom, teachers frequently talked about responsibilities of the children and how these responsibilities are monitored. It is evident that children support the teacher in ensuring classroom order with the responsibilities they undertake. Asli explained this as:

If I expect collaboration from them in the classroom I give them task definitions, I give them duties and monitor whether or not the children fulfill them. For example, wiping the desk, giving the task of checking classroom sound to one of the children. We usually get positive feedbacks from the classroom, children establish a good collaboration.

The most important point about child collaboration that the participant teachers emphasized 
was the collaboration the teacher establishes with the child's peer. The teacher's burden concerning classroom order and supporting individual work of the children decreases as a result of this collaboration and they avoid the need of adopting an interfering approach. Data collected from the interviews indicate that keeping 3-6 year-old children in the same Montessori environment results with elder children helping and guiding the children who are younger than them. This solidarity that occurs in a natural process can sometimes occur with the guidance of a teacher. Seval expressed these about the subject:

When you collaborate with children from the previous year, then they become very precious. Because they are the elder brother and sisters of the classroom and the other children follow them with admiration. You need to be in good terms with them. If you make them feel valuable then they can manage your classroom when you are not there.

Participant teacher Jane stated that the learning process is carried out through the collaboration between the child and the teacher. When the activities presented by the teacher are interesting and when the teacher adopts an approach that the child can understand during the learning process, then this will enable the child to understand the message and as a result learn.

[...] the kind of activities that you put: If those activities are engaging to the child and the child is learning something from them. This is the way you are collaborating with the child. Another way is deliver your lesson. It is delivering your lesson in a way that the child is understanding: That's kind of a collaboration. (Jane)

When teacher statements are considered, it is evident that materials are one of the ways of establishing collaboration with the child during learning. Keeping the materials in an order and ensuring shelf order guides the children during learning. In addition, it was observed that keeping the materials available in different ways in the classroom offers a variety in learning and positively affects the approach of the child towards learning.

One of the 3-6 Montessori learning settings is the practical life area. It is clear in teacher statements that one other dimension in the collaboration they establish for including the child in daily life is related to collaboration with the child's peers and other adults in the setting. Fulya explained that she tries to spread the collaboration established during learning to a wider area than the Montessori practical life area: "I prefer including everything that the child will experience and encounter during daily life with respect to collaboration."

\section{Challenges Experienced in Communication and Collaboration}

According to the interviews, it was observed that teachers face various difficulties in ensuring communication and collaboration. These difficulties were examined under the titles: time management, orientation period, crowded learning environment, deviation and administrative pressure on subjects chosen for circle time activities. Categories created based on these subjects are summarized in Figure 3. 


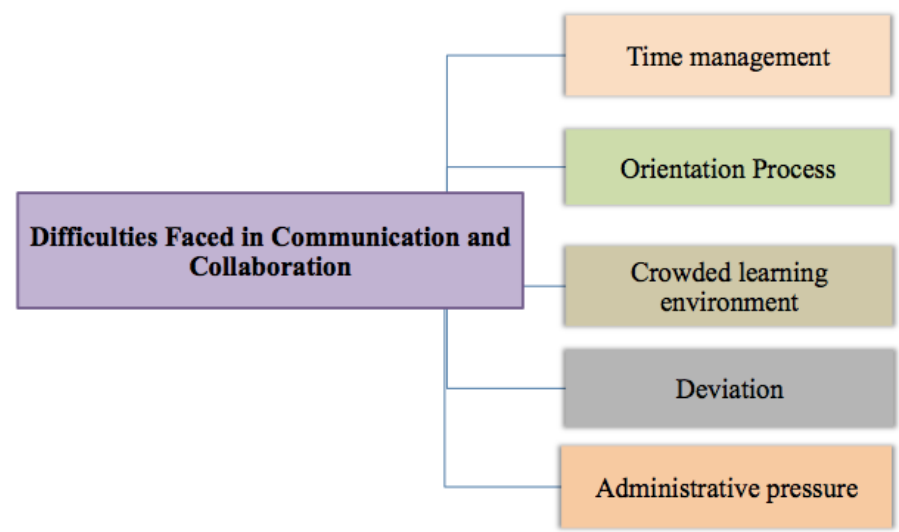

Figure 3. Categories examined under the difficulties faced in communication and collaboration theme

The 3-6 age group is together in Montessori preschool learning environments and an individual education program is majorly conducted. From time to time teachers encounter this as a difficulty in establishing one-to-one communication with each child throughout the day. Asli expressed that conducting one-to-one work during busy terms in a crowded learning environment becomes difficult:

The whole class cannot be completed in one day. You need to make a good schedule for this and presentations of the children can sometimes take long. [...] For example you have non-class work. You may need to complete them too. Parent teacher meetings or report days can take too long. We can have difficulties on these issues, this is the hardship of working with the children individually. [...] I believe that many teachers agree on this in the system. Because we try to deal with the children one-to-one. We strive to deal with them one-to-one and fulfill their needs.

Participant teachers referred to the difficulty of setting an order at the beginning of the academic year in the classroom with children who are new with the Montessori learning environment. Ümran stated this difficulty as "It is really difficult at the beginning. I am telling you this from the point of view of the children who are unfamiliar with the Montessori system". Teachers stated that there could be a problem from time to time in ensuring order and carrying out the responsibility of putting back the material to its place especially during the orientation period. It was underlined that communicating through a consistent attitude is a key point in equipping the child with the necessary behavior. It was stated that the orientation period takes place again when a new child enters the classroom in the middle of the semester. It is evident that this leads to a hardship.

Teachers emphasized reminders and rules concerning their collaboration with the children so as to ensure classroom order. A turn towards a teacher-centered approach may occur from these frequent statements. Also, when various teacher approaches towards incompatible children are examined, it can be asserted that there is a change towards behaviorism. Participant teachers stated that sanctions were applied as a result of the persistent attitude of children who displayed unwanted behaviors. With this respect, it was underlined that sanctions are not punishments and sanctions and punishments are different concepts. Fikriye's statement on this issue is: 
Let's say a child is constantly annoying his friends. We first make warnings to this child. Then, we apply slight sanctions. [...] But it is important to tell the child beforehand. This is where it differs from punishment. I mean this is not a punishment, I am reminding you. I don't want you to lose this time. Because I know you love garden time. But if you continue doing this, then it is your choice and responsibility that you lost 5 minutes from garden time. We actually attach the responsibility of the result of the behavior on the child.

In implementations of various teachers it was observed that children who continue to display negative behaviors in the circle remain out of the circle as an audience for a while. Asli stated that although she takes precautions so that unwanted behaviors won't be displayed in the circle, and explained her approach in cases where a negative state occur.

If I see that they annoy the circle too much, then they have three warnings. I mean they have to watch the circle from a bit distance at the third warning. Next to my circle we have a story corner. I say they can listen to the circle from the story corner but I can't keep them there for too long. I keep them there for a short time. Then I say you can come back to the circle, but they have three rights up to that point.

In times where children fail to solve conflicts and disagreements on their own, teachers guide the children in finding solutions. There can be times when it becomes difficult to carry out this guidance as a result of the high number of children in the classroom. Gülten expressed this as:

This disagreement is usually about materials. [...] One says I took it, the other says it was my turn I took it. Then I say okay you both have to work with different materials I have to put this away. The problem is cleared away when the material is put away. This is my solution, it might be wrong though. Unfortunately, there can be instant solutions because there are too many children in the classroom, there are 19 children right now.

The mixed-aged group activity can lead to various difficulties during the circle time presentations. Firstly, the subjects should be identified appropriate for all children between 36 years old. Secondly, children who have participated in the same learning environment for three years may not be interested in the presentations and get bored. The presentations that have been chosen for the circle time should take these situations into consideration. However, that teacher opinions are not considered when identifying the subjects that they are going to present emerges as administrative pressure. Ayça, who participated in the interview, expressed that:

For example we talked about natural disasters: Volcano, avalanche. Our small age groups got very scared, especially girls. I state that every subject shouldn't be presented during the circle hour but unfortunately this is what the school desires. Such subjects shouldn't be expressed during the circle hour and children who have come to the same school for 3 years get bored from listening to the same things over and over again.

\section{Conclusion, Discussion and Recommendations}

This study aims at examining communication and collaboration experiences between children and the teacher in preschool learning environments that adopted the Montessori method. With respect to the findings, it can be stated that the experiences of Montessori teachers and the Montessori philosophy are mostly in line but can contradict at some states. 
The findings indicate that especially the guidance and observer roles of Montessori teachers direct the communication established between the teacher and child. Roles of Montessori teachers are defined as; one who prepares the learning environment, who is an observer, guide and educational leader (Aljabreen, 2017; Montessori, 2004). In this study, participant teachers stated that they identify individual differences and needs of the children based on their observations and shape their communication with the child accordingly. The Montessori method is carried out as a system that takes notice of the child's needs (Dapolito, 2016; Montessori, 2009; Schmidt \& Schmidt, 2009) and respect to the child, which is one of the primary principles the method is based on (Isaacs, 2018; Pickering, 1992). A communication that attaches value and reliability on the child and which listens to and cares about the child places respect to the child in the basis. With this respect, it can be stated that in the communication they establish with children the participant Montessori teachers show respect and love to the child and also, based on their observations, follow a line that takes into consideration the individual differences and needs of the child.

One of the categories examined concerning communication was greeting. Data collected from the interviews revealed that teachers place importance to greeting the child in the morning. Greeting, which is the starting point of daily life communication, has an effect on the child to start the day in trust. Greeting children in the morning support their social-emotional development. According to the study conducted by Haslip, Allen-Handy, and Donaldson (2019), greeting children in the morning is regarded as kindness behavior of teachers. Teachers' kindness behaviors help to build a positive environment, secure relationships, and prosocial behaviors. Similarly, Murayama et al. (2020) found that children greeting the people in their close environment increase the bond they establish with their environment and the increase in the frequency of greetings contributes to their prosocial behaviors. Schmidt and Schmidt (2009) underlined the greeting during the daily flow implemented for Montessori 3-6 age groups. It can be stated that one-to-one greeting that takes place in the morning is generally displayed in Montessori schools (Kennedy, 2019; Schmidt \& Schmidt, 2009). It is evident that the greeting circle that most of the participant teachers implement is the preference of the teacher. When mentioning about the observations in the Montessori Children's House with respect to greeting the child, Feez (2009) stated that every child shakes hands with the teacher at the entrance in the morning. The majority of the teachers interviewed have adopted a more intimate approach like hugging during morning greetings. When it is considered that the Montessori method was spread throughout other continents starting from Italy then Europe (Feez, 2009), it can be stated that the reason why physical contact level of participant teachers has extended beyond handshaking is due to cultural differences. In the comparative study conducted by Aljabreen (2017) on a Montessori school in the United States of America and a traditional preschool in Saudi Arabia, it was discovered that the greeting and communication in general between the teacher and child in both schools differs. In this study, based on the statements of teacher Jane, who was raised in an environment different from the Turkish culture (a part of South Asia), Turkish culture has a reflection on the communication between the teacher and child. It can be assumed that this is due to the differentiation of the statements preferred during greetings among societies, which is based on cultural difference (Keskin, 2017). Obtained data indicates that Turkish teachers and children prefer a closer and more intimate communication. Thus, it is assumed that studies on comparing the implementation of the Montessori method in different cultures will contribute to the field.

The findings indicated that teachers used polite statements in communication. It was observed that especially during the orientation period, circle time implementations had the aim of 
making rules of politeness and manners a habit for children. Teachers, who are role model by using polite statements in communication, stated that; they adopt a polite approach through body language, voice tone, gesture and facial expressions. Preferring grace and courtesy in communication constitutes a model for children in school environments where social learning takes place. In the Montessori method, grace and courtesy implementations are integrated within education and presented to the child and are applied constantly (Montessori, 2009; Sackett, 2015).

According to the findings of this study, participant teachers collaborate with the children while setting classroom rules. Teachers conducting implementations on democratic rule making, include the child in identifying classroom rules and enable the child to collaborate with the teacher. Guiding children to act in a self-disciplined manner is underlined in the Montessori method (Edwards, 2002). The Montessori approach stresses developing selfdiscipline rather than externally controlling the child. Therefore, ensuring peace and compromise in practice within the classroom is possible by including the child in the rule making process and the child adapting to these rules (Duckworth, 2008).

Results showed that teachers provided collaboration with the child through materials during learning. The Montessori method, which is child-centered, progresses through the support given from the guide teacher and environment to the child (Baynham, 2016). Lillard (2018) stated that regulations that are based on collaboration in learning will contribute to the learning of the child. One of the parts of these regulations is, for the children to shape their own success, the Montessori teacher preparing the environment by presenting stimuli according to the critical periods and by taking the children's interest (Schmidt \& Schmidt, 2009). Thus, ensuring teacher and child collaboration during learning takes place when the prepared environment appeals to the child both developmentally and individually and when the child shapes his self-learning. In summary, prepared environment and the guidance provided by the teacher to the child constitute collaboration.

Participant teachers of this study emphasized the support children get from their elder peers and the responsibilities children undertake in the classroom and the monitoring process of these. Wana (2010) states that in Montessori environments children learn to take responsibility and as a result of this responsibility, they learn to respect the environment and others. Developing behaviors by learning from imitation increases in the Montessori environment implemented through mixed-aged groups (Lillard, 2018). Elder children serve as a model by helping younger children; younger children take elders as an example. It can be stated that teacher emphasis on the support they get from the peers of the children when establishing child collaboration is in line with the literature.

One of the outstanding issues concerning the difficulties that Montessori teachers encounter in child communication and collaboration is teacher approaches in cases of conflict and disagreement. The participants stated that in cases of conflict and disagreement they firstly observe the situation and do not interfere, but when it is required to interfere they display an attitude of listening to both sides and being fair. It can be asserted that this attitude is parallel with the behavior underlined in the Montessori education of sustaining the human dignity of both children in cases of conflict (Duckworth, 2008).

According to teacher statements in general, it is evident that they prefer a positive and constructive language when approaching the child. It is known that Maria Montessori attaches importance on peace education. The effectiveness of peace education is related to the teachers 
and administrators being a role model (Duckworth, 2008). With respect to ensuring a peaceful atmosphere in the classroom, various teachers stated that sanctions were applied on children who insisted on displaying unwanted behaviors. Sanctions were referred to as deprivation of various rights as a result of the child failing to sustain his responsibility. According to the related literature, the responsibility of free movement given to the child can be taken back as a result of the child misusing his freedom (Lillard, 2007). When practices of participant teachers are considered, it is clear that the situation that the child is deprived of is when the desired stimulus is taken away from the environment, in other words, type two punishment. This implementation refers to a change from progressive philosophy towards a behavioral approach. A similar change can be observed in orientation process when setting the rules. Based on teacher expressions stating they make many warnings about applying rules, it can be stated that there is a change from learner-centered approach towards a teachercentered approach. It was emphasized that teachers, who provided guidance about adapting to rules at the beginning, constantly made reminding and warnings to the children so that they will embrace the rules. When the related literature is considered, it is evident that strictly applying the rules in the Montessori environment can have a restrictive effect on children achieving their potentials (Mietzitis, 1971). With this respect, it can be stated that the reason why teachers underline rules can be due to the fact that the process of the Montessori method is based on the application of various rules. Therefore, further research might examine the Montessori method, which provides the child freedom within limits, based on the characteristics and operation of the rules could be.

It was identified that one of the difficulties Montessori teachers face concerning child communication and collaboration is encountering administrative pressure when selecting the subjects presented in the circle. The fact that the circle time activities for specific subjects leads to a case of avoiding the individual differences and needs of the children. Based on this, it is necessary for schools, which adopted the Montessori philosophy, to embrace the same philosophy in their administrative structure. According to Chisnall's (2011) study, it was found that teachers encounter conflict and resistance when their administration and team friends misunderstand the Montessori philosophy. Future studies can examine the administrative drawbacks that Montessori teachers face in implementing the Montessori method.

Concerning communication and collaboration with the child, the crowded number of children was an issue that Montessori teachers had to deal with. Teachers had difficulty managing time to communicate and collaborate with the children during the uninterrupted work cycle because they communicated with the children most of the time individually. In other studies, the large number of children in Montessori learning environments was also reported as a challenge Montessori teachers cope with (Aksoy, 2020; Sak, 2014).

In conclusion, in this phenomenological study, child communication and collaboration established with Montessori teachers was examined according to the teachers' perspective and contributing to the teachers and researchers working in this field was aimed at. This study is limited with the experiences of 12 Montessori teachers in Turkey. Obtained data were examined according to the communication and collaboration between only the teacher and child. When the literature is considered, it is clear that there are few studies that directly examine the communication and collaboration between the child and teacher. Further studies on this subject, would be worthwhile to use different research methods and techniques and also to examine the comprehensive sub-titles one-by-one and in detail. 


\section{References}

Aksoy, P. (2020) Montessori yaklaşımının uygulandığı sınıflarda görev yapan okul öncesi öğretmenlerinin Montessori yaklaşımının "farklı, güçlü ve zorlayıcı yanları” na ilişkin görüşleri: Amerika ve Türkiye örneği [The views of the preschool teachers working at classes where Montessori approach is applied on the "different, strong and challenging" sides of the Montessori approach: the case of America and Turkey]. Eurasian Journal of Social and Economic Research, 7(10), 278-309.

Aljabreen, H. (2017). A comparative multi-case study of teacher roles in US Montessori preschool and Saudi public preschool (Doctoral dissertation, Kent State University).

American Montessori Society (2021). 5 core components of Montessori education. Retrieved from: https://amshq.org/About-Montessori/What-Is-Montessori/Core-Components-ofMontessori

Baynham, H. J. (2016). Çocuğun ayak izinden [Tracing the footprint of the child]. İstanbul: Optimist Yayınları.

Bărbieru, I. T. (2016). The role of the educator in a Montessori classroom. Revista Românească pentru Educaţie Multidimensională, 8(1), 107-123.

Berg, B. L., \& Lune, H. (2019). Sosyal bilimlerde nitel araştırma yöntemleri [Qualitative research methods for the social sciences]. Konya: Eğitim Yayınevi.

Berg, B. L. (2004). Methods for the social sciences. Qualitative Research Methods for the Social Sciences. Boston: Pearson Education, 191.

Brock, Jessica S. (2017). The effects of music and visual cues on transition time in a multiaged 3-5 year old Montessori classroom. Retrieved from Sophia, the St. Catherine University repository website: https://sophia.stkate.edu/maed/211

Chamberlain, B. (2009). Phenomenology: A qualitative method. Clinical Nurse Specialist, 23(2), 52-53.

Chisnall, N. (2011). Montessori education in Aotearoa-New Zealand: A framework for peace and social justice (Doctoral dissertation, Auckland University of Technology).

Converse, M. (2012). Philosophy of phenomenology: How understanding aids research. Nurse researcher, 20(1), 28-32.

Creswell, J.W. (2012). Qualitative inquiry and research design: Choosing among five traditions. California: Sage Publications.

Dapolito, A. F. (2016). Implementation of self-regulation and conflict resolution strategies through conscious discipline in an early childhood classroom. Retrieved from Sophia, the St. Catherine University repository website: https://sophia.stkate.edu/maed/154

Dereli, E. (2017). Montessori eğitim programinin çocuklarin psikososyal gelişimlerine ve sosyal problem çözme becerilerine etkisinin incelenmesi [Investigation of the effects of the Montessori educational program on children's psychosocial development and the social problem solving skills]. Ahi Evran University Journal of Kırşehir Education Faculty, 18(2), 135-153.

Duckworth, C. (2008). Maria Montessori and peace education. Encyclopedia of peace education, 33-37.

Duckworth, C. (2006). Teaching peace: a dialogue on the Montessori method. Journal of peace education, 3(1), 39-53.

Edwards, C. P. (2002). Three approaches from Europe: Waldorf, Montessori, and Reggio Emilia. Early Childhood Research \& Practice, 4(1), 1-16.

Ender, D., \& Ozcan, D. (2019). Self-efficacy perceptions of teachers on using the Montessori method in special education in North Cyprus. Cypriot Journal of Educational Sciences, 14(4), 652-660. 
Estes, A. (2018). Perceptions of adult-child collaboration in toddler environments in a midwestern Montessori School (Unpublished Doctoral Thesis). Hamline University, School of Education.

Feez, S. (2009). Montessori and early childhood: A guide for students. London: Sage Publications.

Firdaus, I. (2018). The application of Montessori method to a child's development in English reading and writing skills (case study). Pujangga, 3(2), 144-179.

Flynn, T. M. (1991). Development of social, personal and cognitive skills of preschool children in Montessori and traditional preschool programs. Early Child Development and Care, 72(1), 117-124, doi: 10.1080/0300443910720111

Fraenkel, J. R., Wallen, N. E., \& Hyun, H. H. (2011). How to design and evaluate research in education. New York: McGraw-Hill Humanities/Social Sciences/Language.

Greene, P. K. (2005). Dear Maria Montessori. Kappa Delta Pi Record, 41(4), 164-166, doi: 10.1080/00228958.2005.10532064

Harris, I. M. (1995). Teachers' response to conflict in selected Milwaukee Schools. Retrieved from https://files.eric.ed.gov/fulltext/ED393855.pdf

Haslip, M. J., Allen-Handy, A., \& Donaldson, L. (2019). How do children and teachers demonstrate love, kindness and forgiveness? Findings from an early childhood strengthspotting intervention. Early Childhood Education Journal, 47(5), 531-547. doi: 10.1007/s10643-019-00951-7

Hiles, E. (2018). Parents' reasons for sending their child to Montessori schools. Journal of Montessori Research, 4(1), 1-13.

Isaacs, B. (2018). Understanding the Montessori approach: Early years education in practice. Abingdon: Routledge

Keskin, A. (2017). Türk kültüründe "selamlaşma" ve "vedalaşma" hakkında genel bir değerlendirme [A general assessment about "greeting" and "saying good bye" in Turkish culture]. TURKISH WORLD, Journal of Language and Literature, (43), 125 146.

Kusumawardani, L., Nani, D., \& Sulistiani, S. (2020). Improving gross motor skill development through the Montessori method in children aged 3-5 years. Sri Lanka Journal of Child Health, 49(4), 347-352.

Lillard, A. S. (2018). Montessori. Dehanin Ardındaki Bilim [The science behind the genius]. İstanbul: Kaknüs Yayınları.

Lillard, A. S. (2007). Montessori. The science behind the genius. New York: Oxford University Press.

Lillard, A. S. (2013). Playful learning and Montessori education. NAMTA Journal, 38(2), 137-174.

Lillard, A. S. (2012). Preschool children's development in classic Montessori, supplemented Montessori, and conventional programs. Journal of School Psychology, 50(3), 379401, doi: 10.1016/j.jsp.2012.01.001

Lillard, A. S., \& McHugh, V. (2019). Authentic Montessori: The Dottoressa's view at the end of her life part I: the environment. Journal of Montessori Research, 5(1), 1-18.

Merriam, S. B., \& Tisdell, E. J. (2015). Qualitative research: A guide to design and implementation. San Francisco, CA: John Wiley \& Sons.

Miezitis, S. (1971). The Montessori method: Some recent research. Interchange, 2(2), 41-59.

Miles, M. B., \& Huberman, A. M. (1994). Qualitative data analysis: An expanded sourcebook. California: Sage Publication.

Montessori, M. (2009). The discovery of the child. New York: Montessori-Pearson Company. 
Montessori, M. (2013). The Montessori method. New Brunswick, NJ: Transaction publishers.

Montessori, M. (2004). The Montessori method: the origins of an educational innovation: including an abridged and annotated edition of Maria Montessori's The Montessori method. Rowman \& Littlefield.

Murayama, S., Kuraoka, M., Nonaka, K., Tanaka, M., Nemoto, Y., Yasunaga, M., ... \& Fujiwara, Y. (2020). School students' greeting behavior and its association with their community attachment and helping behavior. Japanese Journal of Public Health, 67(7), 452-460, doi: 10.11236/jph.67.7_452.

Mushamba, A., Burney, S. F., \& Kent, J. (2017). The impact of Montessori practices (Unpublished Doctoral dissertation). Lipscomb University, Nasville, U.S.A.

Ornstein, A. C., \& Hunkins, F. P. (2016). Eğitim programı: temeller, ilkeler ve sorunlar (Çev. Komisyon) [Educational program: fundamentals, principles and problems]. Ankara: Eğitim Yayınevi.

Pickering, J. S. (1992). Successful applications of Montessori methods with children at risk for learning disabilities. https://doi.org/10.1007/BF02654940 , 42, 90-109.

Sackett, G. (2015). Grace and courtesy: empowering children, liberating adults. Namta Journal, 40(1), 113-126.

Sak, İ. Ş. (2014). Okul öncesi öğretmen adaylarının Montessori ve Reggio Emilia yaklaşımları ile ilgili görüşleri [The views of pre-service preschool teachers regarding Montessori and Reggio Emilia approaches]. Inönü University Journal of the Faculty of Education, 15(3), 1-20.

Saldaña, J. (2013). The coding manual for qualitative researchers. Sage Publication.

Sarı, R. M., \& Türk, S. A. (2020). Montessori okullarında mekânı kavramlarla okumak [Reading the space with concepts in Montessori schools]. Journal of Art and Design, 10(1), 82-105.

Schmidt, M., \& Schmidt, D. (2009). Understanding Montessori: A guide for parents. United States of America: Dog Ear Publishing.

Signorello, A. V. (2017). The Montessori system as education for peace. (Unpublished Master of Arts Thesis) Saint Mary's University, Halifax, Canada.

Thayer-Bacon, B. (2011). Maria Montessori: education for peace. Factis Pax, 5(3), 307-319.

Türnüklü, A. (2000). Eğitimbilim araştırmalarında etkin olarak kullanılabilecek nitel bir araştırma tekniği: Görüşme [A qualitative research technique that can be used effectively in educational researches: Interview]. Educational Administration: Theory and Practice, 24(24), 543-559.

Wana, J. (2010). How to choose the best preschool for your child: the ultimate guide to finding, getting into, and preparing for nursery school. Illınois: Sourcebooks, Inc..

Wentworth, R. A. L., \& Wentworth, F. (2013). Montessori for the New Millennium: Practical guidance on the teaching and education of children of all ages, based on a rediscovery of the true principles and vision of Maria Montessori. Taylor \& Francis.

Whitescarver, K., \& Cossentino, J. (2008). Montessori and the mainstream: A century of reform on the margins. Teachers College Record, 110(12), 2571-2600. 